\title{
EL HOSPITAL DE VENERABLES SACERDOTES DE SEVILLA: ALGUNAS CONSIDERACIONES SOBRE EL EDIFICIO Y EL PAPEL DESEMPEÑADO POR LOS ARQUITECTOS JUAN DOMÍNGUEZ Y LEONARDO DE FIGUEROA
}

\section{THE VENERABLE PRIESTS HOSPITAL IN SEVILLE: SOME CONSIDERATIONS ABOUT THE BUILDING AND THE ROLE PLAYED BY THE ARCHITECTS JUAN DOMÍNGUEZ AND LEONARDO DE FIGUEROA}

\author{
Teodoro Falcón Márquez \\ Universidad de Sevilla. España \\ tfm@us.es
}

\begin{abstract}
Aunque tradicionalmente se ha considerado que el Hospital de Venerables Sacerdotes fue iniciado por Juan Domínguez y terminado por su discípulo Leonardo de Figueroa, en este artículo se resalta el papel desempeñado por este último desde 1686, hasta la conclusión del edificio en 1699. Nunca hubo relación maestro-discípulo. En 1686, Leonardo era un arquitecto consagrado, maestro mayor del Hospital de la Caridad, quien percibía desde el primer momento el doble que Domínguez. En los Venerables, Figueroa fue el artífice de la construcción de las fachadas, de la fisonomía de la escalera principal, del acabado de la iglesia, de la construcción de la espadaña, de los cuartos, así como del patio trasero de columnas.

Palabras clave: Barroco sevillano; Hospital de Venerables Sacerdotes; Juan Domínguez; Leonardo de Figueroa; Justino de Neve.
\end{abstract}

Although it has traditionally been considered that the Venerable Priests Hospital was started by Juan Domínguez and finished by his disciple Leonardo de Figueroa, this paper highlights the role played by the latter from 1686 until its conclusion in 1699. There was never a master-disciple relationship. In 1686 Leonardo was a consecrated architect, master of the Charity Hospital, who perceived the double that Dominguez from the first moment in the Venerable Priests Hospital. Figueroa was the architect of the construction of the facades, the physiognomy of the main staircase, the finish of the church, the construction of the bulrush and the rooms, as well as the backyard of columns.

Keywords: Sevillian Baroque; Venerable Priests Hospital; Juan Domínguez; Leonardo de Figueroa; Justino de Neve. 


\section{EL ESTADO DE LA CUESTIÓN Y EL MARCO URBANÍSTICO}

La antigua Casa de Señores Venerables Sacerdotes de Sevilla ${ }^{1}$ forma parte de los grandes edificios asistenciales, como el Hospital de la Caridad, que se construyeron en esta ciudad tras la epidemia de peste de 1649, cuando se redujo su población prácticamente a la mitad. De esta institución hay ya una notable bibliografía, en la que se ha abordado su fundación en 1675 por el canónigo Justino de Neve, con la colaboración de varias personalidades; la donación y permuta de terrenos para la construcción del inmueble; la labor desarrollada por los arquitectos Juan Domínguez y Leonardo de Figueroa; el patrimonio cultural y artístico que atesora; así como los diversos usos que ha tenido en los siglos XIX y XX, hasta convertirse en sede de la Fundación Fondo de Cultura de Sevilla (FOCUS $)^{2}$. Esta institución hospitalaria tiene como antecedentes vínculos con la Hermandad del Silencio y una Casa-Hospicio de Venerables Sacerdotes, establecida inicialmente en la ermita de San Blas, que con posterioridad se trasladó al Hospital de San Bernardo (vulgo de los Viejos). El principal artífice del nuevo hospital, en el barrio de Santa Cruz, fue el canónigo Justino de Neve, amigo de

${ }^{1}$ Así figura en el Libro de la obra que por cuenta del Ilmo. Sr. D. Jaime Palafox y Cardona se está haciendo en esta Casa de Señores Venerables Sacerdotes de esta dicha ciudad (1696-1697). AGAS (Archivo General del Arzobispado de Sevilla), Hospital de los Venerables, sección Fábrica, leg. 4, lib. ${ }^{\circ} 5$.

${ }^{2}$ ORTIZ DE ZÚÑIGA, Diego: Anales Eclesiásticos y Seculares de la ... ciudad de Sevilla. Vol. V. Sevilla, 1677 (reed. Madrid, 1796); PONZ, Antonio: Viage de España. Vol. IX. Madrid, 1786, pp. 790-795; ARANA DE VARFLORA, Fermín: Hijos de Sevilla ilustres en santidad, letras armas, artes o dignidad. Vol. III. Sevilla, 1791 (reed. 1996), pp. 69-70; MATUTE Y GAVIRIA, Justino: Noticias relativas a la Historia de Sevilla. Sevilla, 1828 (reed. Sevilla, 1886 y Sevilla, 1982), pp. 139, 161 y 163; GONZÁLEZ DE LEÓN, Félix: Noticia artística de todos los edificios públicos de esta muy noble ciudad de Sevilla. Sevilla, 1844 (reed. 1973), pp. 416-417; COLLANTES DE TERÁN, Francisco: Memorias históricas de los establecimientos de Caridad de Sevilla. Sevilla, 1884, pp. 273-290; GESTOSO Y PÉREZ, José: Sevilla Monumental y Artística. Vol. III. Sevilla, 1892, pp. 358-366; SANCHO CORBACHO, Antonio: Arquitectura barroca sevillana del siglo XVIII. Madrid, 1952, pp. 49-54; ANGULO ÍÑIGUEZ, Diego: "Casa de Venerables Sacerdotes", Boletín de la Real Academia de Bellas Artes de Santa Isabel de Hungría, IV, 1976, pp. 45-93; RUBIO, Pedro y ROTTHOFF, Petra: Inventario del Archivo de la Hermandad de los Venerables Sacerdotes y su Casa-Hospicio de San Pedro y San Fernando de Sevilla. Sevilla, 1990; AA.VV.: Los Venerables. Sevilla, 1991; FALCÓN MÁRQUEZ, Teodoro: "Algunas puntualizaciones sobre los hospitales de los Venerables y de la Caridad", Laboratorio de Arte, 11, 1998, pp. 183-194; QUILES GARCÍA, Fernando: Teatro de la Gloria. Sevilla, 2007, pp. 384-387; y CHILLÓN RAPOSO, David: "Nuevas aportaciones sobre el Hospital de los Venerables Sacerdotes de Sevilla", Anuario de la Iglesia Andaluza, III, 2010, pp. 200-225. 
Murillo $^{3}$, promotor de la reconstrucción de la iglesia de Santa María la Blanca y de las fiestas de canonización de San Fernando en la catedral (1671).

Desde el primer cabildo celebrado por la hermandad, el 26 de abril de 1676, se nombró un presidente eclesiástico, siendo el primero Justino de Neve; más un presidente secular, Fernando Villegas, marqués de Paradas ${ }^{5}$. Neve estuvo al frente de la institución, saliendo siempre reelegido, hasta su fallecimiento el día 12 de junio de 1685. Los presidentes seculares, sin embargo, cambiaron con frecuencia, aunque se repitió el de Pedro Colbert. Justino de Neve, que buscó apoyo en la corte pontificia en la persona de su representante, el cardenal Alderano Cibo, contó con la colaboración de miembros del cabildo catedral, entre los que figuraron los canónigos Luis Corbet, Luis Federigui y Juan de Loaysa. De los seglares colaboraron aristócratas como Pedro Manuel Colón de Portugal (1651-1710), almirante, duque de Veragua y conde de Gelves, además del marqués de Paradas y del marqués de la Peñuela, entre otros. Entre los grandes colaboradores de Neve, que además aportaron grandes cantidades para la construcción del hospital, hay que destacar a miembros de la familia Colbert. En primer lugar a Roberto Colbert, caballero de la Orden de Calatrava y caballero veinticuatro de esta ciudad, quien donó por vía testamentaria a esta hermandad mil ducados. Estaba casado con doña María de $\mathrm{Cea}^{6}$. Un hijo de ambos, Luis, canónigo de la catedral, figura como consiliario eclesiástico en el primer cabildo de 26 de abril de $1676^{7}$. Por último citaremos al otro hijo, Pedro Colbert, almirante, a quien dedicamos un apartado más adelante. Entre otros hay que destacar el apoyo y ayuda económica del

${ }^{3}$ Véanse varios ensayos en el catálogo de la exposición Murillo y Justino de Neve. El arte de la amistad. Madrid-Sevilla-Londres, 2012.

${ }^{4}$ FALCÓN MÁRQUEZ, Teodoro: La iglesia de Santa María la Blanca y su entorno. Arte e Historia. Sevilla, 2015.

${ }^{5}$ AGAS, Hermandad de los Venerables, sección Reglas y Estatutos, leg. 1, n ${ }^{\circ}$ 6, Borrador de acuerdos tomados por la Hermandad referente a los acuerdos tomados desde 1676 a 1686 (1743), s. f.

${ }^{6}$ Ibidem, sección Patronatos, leg. 11, $\mathrm{n}^{\circ}$ 4, Documentos referentes al Patronato de los señores Corbet (sic). QUILES GARCÍA, Fernando: Teatro de la Gloria, op. cit., p. 386; y ESPINOSA Y CÁRCEL, Antonio María: Ilustraciones y correcciones a los Anales de Ortiz de Zúñiga. T. V, lib. XVII. Sevilla, 1883, pp. 440-445.

${ }^{7}$ Fue designado albacea en el primer testamento de Justino de Neve, fechado en 29 de septiembre de 1677. AA.VV.: Murillo y Justino de Neve, op. cit, p. 153. Además de otras aportaciones económicas con destino al hospital, entregó la Prestamera de los Palacios, valorada en unos tres mil ducados. ESPINOSA Y CÁRCEL, Antonio María: Ilustraciones y correcciones..., op. cit., pp. 440-441. 
propio Justino de $\mathrm{Neve}^{8}$ y del capitán Juan Ribón ${ }^{9}$, así como de los prelados don Ambrosio Spínola y Guzmán (1669-1684) y don Jaime Palafox y Cardona (1694-1701)

Para la nueva edificación hubo que recurrir a donaciones de terrenos y permutas de casas. Así, en 28 de diciembre de 1675, Colón de Portugal, duque de Veragua, permutó ante el escribano Pedro de Gálvez el solar donde había estado el corral de comedias llamado de doña Elvira. Tenía una superficie "de 50 varas en cuadro", en el que había una taberna ${ }^{11}$. Al solar se añadieron al año siguiente casas colindantes, así como unas viviendas en la calle Jamerdana: una perteneciente a la Hermandad de Ánimas del Sagrario y otra propiedad del marqués del Ca$\mathrm{sal}^{12}$. Por la donación del duque de Veragua se le concedió el patronato perpetuo sobre la iglesia del hospital. En la escritura de donación exigía que su escudo de armas debía figurar en el templo, tener reservado una silla en el presbiterio, así como una tribuna que comunicara con sus casas principales ${ }^{13}$. Todavía en cabildo de 30 de junio de 1699 consta la petición del duque exigiendo que se colocara su blasón en la iglesia, y en el patio un texto en el que quedara patente su donación, lo que se aprobó en cabildo de 19 de julio ${ }^{14}$. Sus armas figuran pintadas en una pechina del casquete semiesférico del templo. Esas armas de los duques de Veragua (apellido Colón) constan de un blasón cuartelado: primero, en campo de gules, un castillo de oro; segundo, en campo de plata, un león rampante; tercero, en ondas de azur, islas de oro; cuarto, en campo de azur, cinco áncoras de oro puestas en sotuer y bordura de oro cargada del lema en letras de azur "A Castilla y León nuevo mundo dio Colón". Con respecto a la lápida, se colocó sobre el ingreso a la escalera principal. Copiaremos los últimos renglones: "[...] CUYA HERMANDAD EN SEÑAL DE SU GRATITUD DIO A SU EXCELENCIA

${ }^{8}$ En el citado primer testamento dejó 500 ducados para la construcción del hospital. AA.VV: Murillo y Justino de Neve, op. cit., p. 153. Otras donaciones se hicieron a partir de los siguientes testamentos, consistentes en beneficios de casas, piezas litúrgicas y obras de arte.

${ }^{9}$ Sus albaceas testamentarios hicieron entrega de 150 pesos de plata. QUILES GARCÍA, Fernando: Teatro de la Gloria, op. cit., p. 384.

${ }^{10}$ FALCÓN, Teodoro: "El arzobispo don Jaime de Palafox y Cardona (1642-1701) y sus empresas arquitectónicas en Sevilla", en Fiestas y mecenazgo en las relaciones culturales del Mediterráneo en la Edad Moderna. Málaga, 2012, pp. 391-410.

${ }^{11}$ QUILES GARCÍA, Fernando: Teatro de la Gloria, op. cit., p. 384.

12 AGAS, Hospital de los Venerables, sección Reglas y Estatutos, Copias de escrituras, leg. 10, lib. 8 y leg. 27, $\mathrm{n}^{\circ}$ 2; MATUTE Y GAVIRIA, Justino: Noticias relativas..., op. cit., p. 138; COLLANTES DE TERÁN, Francisco: Memorias históricas..., op. cit., pp. 278279; y QUILES, Fernando: Teatro de la gloria, op. cit., p. 384.

${ }_{13}$ AGAS, Hospital de los Venerables, sección Reglas y Estatutos, leg. 10, no 8, Copia simple de la escritura de adjudicación del Patronato perpetuo sobre la iglesia de este hospital, 28-12-1675; y QUILES, Fernando: Teatro de la Gloria, op. cit., p. 384.

${ }^{14}$ CHILLÓN RAPOSO, David: "Nuevas aportaciones...”, op. cit., p. 219. 


\section{Y SUCESORES EN SU CASA EL PATRONATO DE LA IGLESIA, PARA CUYA MEMORIA SE PUSO EN ESTE PADRÓN. HIZO SU EXCELENCIA ESTA DONACIÓN EN EL DÍA 28 DE DICIEMBRE DEL AÑO 1675".}

Se desconoce quién fue el autor de las trazas. En la escritura citada se alude a la existencia "de diferentes plantas hechas por los artífices para la fábrica de dicho ospicio e iglesia". Subrayamos este dato, porque era frecuente entonces proyectar solo la planta, lo que permitía al arquitecto o arquitectos que intervenían en estos edificios hacer modificaciones en los alzados. Tradicionalmente se ha manifestado que las obras las inició Juan Domínguez y que las concluyó Leonardo de Figueroa, quedando algunas lagunas por resolver respecto cuál fue la labor desarrollada por uno y otro. Las obras se iniciaron el 13 de abril de 1676. Sin embargo ya antes, en junta de 9 de febrero de ese año, se había acordado el traslado de los ancianos sacerdotes a una casa colindante de su solar, en la calle Consuelo, lo que se llevó a cabo con todo boato y solemnidad el día 20 de ese mes, siendo llevados en coches de caballos y palanquines ${ }^{15}$. En el curso de las obras, mientras se construía la iglesia, sirvió de capilla provisional la enfermería baja.

Como veremos a continuación son varios los paralelismos existentes entre este hospital y el de la Caridad. Por una parte, Leonardo de Figueroa fue maestro mayor de las dos instituciones. Otro vínculo, no destacado lo suficiente, es el importante papel desempeñado en ambas instituciones hospitalarias por el almirante general don Pedro Colbert, de la Real Armada del Mar Océano y caballero de la Orden de Santiago, quien no solo fue benefactor de los Venerables, sino que fue nombrado presidente secular de esta hermandad en varias ocasiones. Fue propuesto en cabildo general de 15 julio de 1685, reelegido en 19 de junio de 1698, falleciendo el 11 de octubre de ese año cuando dirigía la fase final de la decoración de la iglesia del hospital, a cuyo estreno por tanto no pudo asistir ${ }^{16}$. Consta en el acta del cabildo de 13 de octubre de ese año la noticia de su fallecimiento, por lo que se planteó la posibilidad de celebrar las honras fúnebres tras la inauguración de la iglesia, prevista inicialmente para el día 19 de ese mes y año ${ }^{17}$. En

${ }^{15}$ COLLANTES DE TERÁN, Francisco: Memorias históricas..., op. cit., p. 274.

${ }^{16}$ Neve le nombró albacea en su segundo testamento (6-1-1681) y en el tercero (29-51685). Asimismo, en el codicilo $n^{\circ} 6$, con fecha de 4 de junio de ese último año, le donó una "lámina que yo tengo del diseño del cuadro que está en la casa y amparo de señores sacerdotes de esta ciudad, en muestra de nuestra amistad". Se refiere a un boceto de La Virgen y el Niño repartiendo pan a los sacerdotes, lienzo realizado por Murillo en 1679 para el refectorio del hospital (Museo de Budapest). AA.VV: Murillo y Neve, op. cit., pp. 154, 161, 162 y n ${ }^{\circ} 18$ del catálogo, pp. 140-141.

17 AGAS, sección Patronatos, leg. 11, no 4, Documentos referentes al patronato de los señores Corbet (sic), f. 5. Falleció sin testar, siendo su heredera universal doña Teresa Peregrina Tirolo Corbet, su prima hermana, casada con don Luis Ignacio de Conique. El almirante se enterró en la capilla mayor de la iglesia de San José del convento de Mercedarias, a raíz del patronato creado por su padre, don Roberto Colbert. ESPINOSA Y CÁRCEL, 
la galería alta del antiguo hospital se conserva un lienzo con el retrato póstumo del presidente Colbert, con el hábito de Santiago, realizado por Lucas Valdés en 1699, siguiendo el modelo generalizado por Murillo, de marco ovalado y el retratado asiendo el marco $(1,28 \times 1,08 \mathrm{~m})^{18}$. Aunque Matute (1886) manifiesta que el arzobispo Palafox bendijo esta iglesia el 14 de septiembre de 1698, lo cierto es que la inauguración se fue dilatando por varias razones. La inscripción existente bajo la imagen de San Fernando, sobre la puerta de la calle Jamerdana, dice: "[...] Estrenóse este templo en 17 de mayo del año de 1699". Resulta un tanto curioso que Pedro Colbert fuera además miembro de la Hermandad de la Caridad, institución en la que fue nombrado hermano mayor tras el fallecimiento de Miguel Mañara el 9 de mayo de 1679. Entre otras intervenciones, como se dirá más adelante, fue quien regaló el Retrato de Don Miguel Mañara a la Hermandad de la Caridad de Málaga. El lienzo fue realizado por Valdés Leal a finales del año 1683, ya que en febrero del año siguiente la hermandad malagueña agradeció el regalo al donante ${ }^{19}$. Por todo ello no es de extrañar la participación de los mismos artífices en las dos instituciones sevillanas. Además de Leonardo, colaboraron en ambos edificios Murillo, Juan de Valdés Leal, Lucas Valdés, Pedro Roldán, Bernardo Simón de Pineda y los maestros marmolistas Francisco Rodríguez Escalona y Silvestre Jordán.

Si analizamos la planta actual del edificio, situado entre medianeras de viviendas y de jardines privados, observaremos que ha experimentado algunos cambios desde su estreno en 1699 hasta la actualidad (Figura 1). El antiguo hospital se organiza en torno al patio principal, de planta cuadrada, de $25 \mathrm{~m}$ de lado, rodeado por una galería con arquerías sobre columnas en cada frente. A la parte central, con fuente en cota más baja, enmarcada por cinco círculos concéntricos de diámetro decreciente, se accede por una escalinata existente en el centro de cada lado. En las crujías de su entorno se halla la fachada principal y puerta de ingreso, orientadas hacia el sur. El vestíbulo, un tanto pequeño, consta de tres tramos, con arquerías sobre columnas pareadas. A eje con la puerta se sitúa una escalinata que accede al patio, que queda descentrado hacia la izquierda. A la derecha del vestíbulo se construyó la casa del administrador, de dos pisos y un

Antonio María: Ilustraciones y correcciones..., op. cit., pp. 440-445; y CHILLÓN RAPOSO, David: "Nuevas aportaciones...", op. cit., p. 214.

18 "Más pagué a D. Lucas Valdés ciento y ochenta rs. y medio de vellón por el retrato que hizo de D. Pedro Corbet, de lo cual tengo recibo". El pago se hizo el 13 de marzo de 1699. ANGULO ÍÑIGUEZ, Diego: "Casa de Venerables Sacerdotes", op. cit., doc. V, p. 90. El almirante fue quien supervisó las pinturas murales que realizó Lucas Valdés en el cuerpo de la iglesia. Según GESTOSO Y PÉREZ, José: Sevilla Monumental... Vol. III, op. cit., p. 365, el retrato se hallaba entonces en el refectorio.

19 Vid. ficha del cuadro por Enrique Valdivieso en Miguel Mañara. Espiritualidad y arte en el barroco sevillano (1627-1679). Sevilla, 2010, pp. 130-131. 
pequeño patio. Se ingresa a él tras una cancela de hierro fechada en 1861. En el frente sur del patio principal se ubicó en planta baja la antigua portería, la escalera principal, la antigua sala de cabildos y el refectorio de verano. Estos últimos espacios se dedican en la actualidad a sede permanente del "Centro Velázquez".

En la crujía de fachada oriental se situó la enfermería baja, de dos naves separadas por una hilera de columnas, que recibe luces por la calle Jamerdana y por el patio a través de sendas ventanas. En el frente de poniente se hallaban las antiguas celdas, hoy desaparecidas. En su lugar hay pequeños patios-jardín. El más moderno, proyectado por el arquitecto Fernando Chueca Goitia en torno a 1990, ha recibido el nombre de San Fernando. La iglesia se halla en la crujía norte. Es de una nave, con orientación este-oeste con testero plano y nártex (vestíbulo) a los pies. Tras su cabecera hay un pequeño patio rectangular que enlazaba con las celdas. Los accesos al edificio son cuatro: la puerta principal al sur, hacia la plaza de los Venerables; al este se abre la puerta de la iglesia, hacia la calle Jamerdana; otro pequeño acceso al oeste comunica un pequeño patio-jardín con la plaza de Doña Elvira a través de una cancela de hierro; y finalmente existe otra puerta, fechada en 1697, que enlaza la diminuta calle Consuelo con el patio ubicado tras la cabecera de la iglesia y las antiguas habitaciones. Esa puerta en el siglo XIX servía de tránsito a los viandantes para enlazar con la plaza de Doña Elvira, según convenio entre el Ayuntamiento y el Hospital, como lo describen González de León y Collantes de Terán. Aunque ese tránsito quedó oficialmente clausurado en 1928, en realidad se mantuvo hasta mediados del siglo XX. El edificio fue rehabilitado en torno a 1990, a raíz de un convenio suscrito entre el arzobispado y la Fundación Focus, fechado el 9 de julio de 1987, por el que se cedía el inmueble a esta institución en régimen de alquiler, tras previa restauración, para usos culturales y artísticos. El proyecto corrió a cargo del arquitecto y académico Fernando Chueca Goitia, con la colaboración de Ramón Queiro Filgueira. El antiguo hospital abrió sus puertas de nuevo en 1992. Al año siguiente Focus recibió el premio "Europa Nostra" al reconocer el valor de la restauración del edificio.

Uno de los aspectos que llama la atención de este inmueble, destinado en origen a asilo y enfermería de ancianos sacerdotes, son las barreras arquitectónicas a causa de la diferencia de cotas del terreno (Figura 2). En el vestíbulo de ingreso hay siete escalones para alcanzar la altura de las galerías del patio; por otra parte, hay dos escalones para acceder a la enfermería baja; la escalinata para comunicar con la calle Consuelo tiene cinco peldaños; además hay que subir la empinada escalera principal; en la planta alta para acceder al coro y tribunas de la iglesia hay que subir cinco escalones. Por último, hay una escalera, hoy renovada, que permite ascender a un mirador-solarium, ubicado sobre el Refectorio de invierno (actual sala de lecturas), en el ángulo suroeste. Con relación a los materiales constructivos, cotejando los documentos, puede observarse que en la fase inicial de las obras se contrataron importantes lotes de columnas de mármol procedentes de Carrara, labradas en Génova, y de Mijas (Málaga). El 7 de noviembre 
de 1676 se trajeron de casa del maestro marmolista José Morales nueve columnas, que se abonaron el 17 de enero siguiente. El primer historiador que las documentó, Angulo Íñiguez, manifiesta después que fueron ocho y labradas por Francisco Rodríguez (Escalona) ${ }^{20}$. Al año siguiente (1677) se trajeron 28 columnas de mármol blanco de Carrara, desde Génova a Sevilla, vía Cádiz, cuyos portes se pagaron en 28 de febrero y 6 de abril ${ }^{21}$. Los números no cuadran, ya que el número de columnas del patio son 20 y las de las enfermerías baja y alta son 10 $(5+5)$, lo que suma un total de 30 columnas. Aquí no se contabilizan otras cinco que se trajeron de la cantera de Mijas, que se colocaron en 1696, bajo la dirección de Leonardo de Figueroa, en el patio ubicado tras la cabecera de la iglesia. Fueron labradas por Silvestre Jordán, a quien le abonaron el 23 de mayo un total de 1.300 reales de vellón ${ }^{22}$. Siendo Sevilla una ciudad que ha empleado tradicionalmente el ladrillo como material básico constructivo, existiendo numerosos hornos alfareros en Triana, resulta un tanto paradójico que en ocasiones se trajeran de Málaga, con el consiguiente coste adicional del transporte. En septiembre de 1678 se abonaron a Francisco Rodríguez (Escalona), maestro marmolista, ciertas cantidades por traer "cuarenta millares de ladrillos que vienen de Málaga para la solería de la Enfermería" - en la actualidad está solado de mármoles- y "ladrillo colorado de Málaga a razón de 14 ducados el millar" 23 . Seguramente se emplearon también para la decoración del patio. Este hecho de traer ladrillos de esa ciudad andaluza no era nuevo en Sevilla. Ya antes, en 1586, se habían empleado en la construcción de la Lonja (Archivo de Indias), al considerarse que eran de mejor calidad los de Málaga ${ }^{24}$.

Durante la etapa final de la construcción del edificio hospitalario, que finalizó en 1699, se hicieron mejoras en su entorno urbanístico. Sin duda lo más significativo fue la apertura de la plaza actualmente rotulada como de los Venerables, que surgió por el retranqueo de la fachada principal del hospital. La plazuela, como se denominaba antiguamente, enlaza con la calle Gloria para acceder a la actual plaza de Doña Elvira; con la calle Jamerdana, en la que se halla la puerta de la iglesia; con la calle Justino de Neve, situada frente a la puerta principal del

${ }^{20}$ ANGUlo ÍÑIGUEZ, Diego: “Casa de Venerables Sacerdotes”, op. cit., p. 49 y doc. 1 , pp. 83-84.

${ }^{21}$ Ibidem, p. 84.

22 AGAS, Hospital de los Venerables, sección Fábrica, leg. 4, lib. nº 5, f. 150. Resulta sorprendente la afirmación de Espinosa y Cárcel, quien manifiesta que "alrededor del patio hay más de 300 columnas de mármol”. ESPINOSA Y CÁRCEL, Antonio María: Ilustraciones y correcciones..., op. cit., p. 446.

${ }^{23}$ ANGUlO ÍÑIGUEZ, Diego: "Casa de Venerables Sacerdotes", op. cit., doc. II, p. 84.

${ }^{24}$ HEREDIA HERRERA, Antonia: La Lonja de mercaderes, el cofre para un tesoro singular. Sevilla, 1992, p. 54. 
edificio, además de una barreduela existente en su frente oriental. En cabildo de 21 de marzo de 1698 se alude a la compra-venta de una casa, de la que se especifica que "del corral le quede hacer una plazuela frente de dicha iglesia" 25 . Tras finalizarse la construcción de las fachadas del edificio en 1697, con sus buhardillas, bajo la dirección de Leonardo de Figueroa, se empedraron las calles circundantes $^{26}$. La calle Jamerdana, que tras la inauguración de la iglesia recibió el nombre de San Fernando, no se adoquinó hasta fines del siglo XIX ${ }^{27}$. En este contexto hay que citar la reconstrucción de la portada y muros de su entorno en el acceso Norte, por la calle Consuelo, que amenazaba ruina en verano de $1695^{28}$. Estas obras se ultimaron dos años después, cuando se concluyeron los cuartos y el patio de tránsito situado tras la cabecera de la iglesia. Entonces se puso esa fecha pintada sobre el dintel, que ha sido sustituida en tiempos modernos por números de cerámica ${ }^{29}$. La calle Consuelo, hoy muy corta y quebrada, enlazaba desde la calle Rodrigo Caro con las actuales plazas de los Venerables y de Doña Elvira.

\section{LOS ARQUITECTOS JUAN DOMÍNGUEZ Y LEONARDO DE FIGUEROA}

Las obras de este hospital se iniciaron el lunes 13 de abril de 1676, día de San Hermenegildo. Dirigiendo las tareas figura Juan Domínguez. Se trata de un maestro alarife con mucho oficio, que fue adquiriendo prestigio mientras estuvo al frente de estas obras, por lo que fue invitado a revisar el estado de otras construcciones. Por todo ello fue nombrado en 1681 maestro mayor superintendente en las obras de la Santa Iglesia Catedral y para las visitas de posesiones, así como maestro mayor del arzobispado. Todo ello en la fase final de su vida. Falleció el 27 de octubre de 1691. En la partida de entierro se especifica que su cuerpo se depositó en la bóveda de la Sacramental, de la que era hermano; asimismo se indica

${ }^{25}$ AGAS, Hospital de los Venerables, sección Reglas y Estatutos, Borrador de Acuerdos..., leg. $1, \mathrm{n}^{\circ} 6$, f. $22 \mathrm{v}$.

${ }^{26}$ Ibidem, leg. 4, no 5: "En 20 [de marzo de 1697] pagó por 134 varas de empedrados que hay en las dos calles inmediatas al portón, que se empedraron de nuevo, las 67 a real y medio, y las otras 67 y medio a 2 rs.". Ibid., lib. 4, Sumas de gastos, cuentas de la iglesia, torre y cajonería de la sacristía y altar de Santa Teresa, f. 41: "Mas pagué por 200 ladrillos toscos de la calle de San Fernando, 16 rs. de vn. a razón de 8 rs. el ciento".

${ }^{27}$ AA.VV.: Diccionario histórico de las calles de Sevilla. Sevilla, 1993, pp. 454-456.

${ }^{28}$ AGAS, Hospital de los Venerables, sección Reglas y Estatutos, Borrador de los Acuerdos..., leg. 1, $\mathrm{n}^{\circ}$ 6, f. 17. Junta de 31 de julio de 1695: "Necesita la casa levantar las tapias que cercan el corral del postigo por estar amenazando ruina, y evitar el riesgo de que no cojan debajo al venerable Don Antonio Villalobos, que se suele arrimar a dichas tapias, que se haga este reparo".

29 AGAS, Hospital de los Venerables, Libro de la obra que por cuenta del Ilmo. Sr. D. Jaime de Palafox..., leg. 4, n 5, f. 149; y ANGULO ÍÑIGUEZ, Diego: "Casa de Venerables Sacerdotes", op. cit., pp. 90-91. 
que era viudo y que vivía en la collación de San Juan de la Palma ${ }^{30}$. Vivía en una posición desahogada como evidencia el hecho de que donara a esta hermandad una casa en la calle Enladrillada ${ }^{31}$, además del pomposo entierro que se costeó.

Sobre este constructor conviene hacer una serie de matizaciones. Cuando se le cita en las nóminas de las cuentas de este hospital iniciadas, como hemos dicho, el 13 de abril de 1676, se alude a él como "maestro de esta obra". Del mismo modo se le cita en años sucesivos. A causa de su creciente prestigio, informó junto a otros maestros de albañilería, el 8 de octubre de 1679, en un reconocimiento de la iglesia de San Jorge en el Hospital de la Caridad. En el informe indica que es "maestro de obras de albañilería y alarife que ha sido de esta ciudad" 32 . En este mismo documento figura Leonardo de Figueroa como maestro mayor del Hospital de la Caridad, como ampliaremos con posterioridad. La primera vez que en las nóminas del Hospital de los Venerables se cita a Domínguez como maestro mayor de esta obra es el 17 de abril de $1684^{33}$. Finalmente consta como maestro mayor de fábricas del arzobispado de Sevilla en un reconocimiento sobre la iglesia del Sagrario, fechado en 16 de julio de $1691^{34}$.

Por todo ello ya dijimos en otra ocasión que cuando en 1676 se puso Juan Domínguez al frente de estas obras era un maestro alarife que no había proyectado ningún edificio de nueva planta. Por eso propusimos que el autor de las trazas debió ser Esteban García (1669-1681), quien desempeñaba entonces los oficios de maestro mayor de la catedral y del arzobispado, autor del proyecto de la iglesia de la colegiata del Salvador, quien contó inicialmente con el mismo equipo de artífices que intervinieron en los Venerables, tales como los maestros canteros Francisco Rodríguez Escalona, Francisco Jordán y el ensamblador Bernardo Simón de Pineda ${ }^{35}$. Debe tenerse presente también en los años iniciales de las obras de este hospital que dos protagonistas de esta institución, como lo fueron los canónigos Justino de Neve y Luis Corbet, llamaron a Juan Domínguez en 1677 para

${ }^{30}$ CRUZ ISIDORO, Fernando: Arquitectura sevillana del siglo XVII. Maestros Mayores de la Catedral y del Concejo hispalense. Sevilla, 1997, pp. 123-126, y FALCÓN MÁRQUEZ, Teodoro: "Algunas puntualizaciones...”, op. cit., pp. 183-185.

31 AGAS, Hospital de los Venerables, Libro de Acuerdos que se inicia en 1681, Junta, 7-7-1685, f. 7v.

${ }^{32}$ HIGUERA MELÉNDEZ, José Manuel: "Leonardo de Figueroa. Inicios y actividad pericial. Una obra y un testamento inéditos", Anuario de Historia de la Iglesia Andaluza, VI, 2013, pp. 9-17; y HIGUERA MELÉNDEZ, José Manuel: "Leonardo de Figueroa. Orígenes, aprendizaje y comienzos del maestro del barroco sevillano", Academia, 114-115, 2014, p. 17.

33 AGAS, Hospital de los Venerables, sección Fábrica, Libro de gastos de las obras (1684-1694), leg. 4, lib. no 3, s. f.

${ }^{34}$ FALCÓN, Teodoro: La capilla del Sagrario de la catedral de Sevilla. Sevilla, 1977, pp. 20 y 74.

35 FALCÓN, Teodoro: “Algunas puntualizaciones...”, op. cit., pp. 184-185. 
reconstruir la iglesia parroquial de la villa de Casaluenga, hoy despoblado en el término de La Rinconada (Sevilla) ${ }^{36}$. Por tanto, estos canónigos son los que debieron contar con un maestro alarife de su confianza, como Domínguez, para que ejecutara el proyecto de Esteban García. Años más tarde Justino de Neve se encargó personalmente de rehabilitar en 1682 la iglesia sevillana de Quema, que se amplió, siendo reconocida por Juan Domínguez ${ }^{37}$.

Con respecto a la labor desempeñada por Leonardo de Figueroa (1654-1730), conviene recordar y resumir qué es lo que sabíamos hasta ahora de su participación en este edificio. Por nuestra parte habíamos manifestado que intervino en dos etapas ${ }^{38}$. La primera en 1686-1687, en la que figura como oficial de albañilería. Tras el paréntesis de su estancia en Carmona, a lo largo de cerca de tres años (1687-1690), volvió a este hospital en 1696 en calidad de maestro mayor de las obras, cargo que simultaneaba con el de maestro mayor del convento de San Pablo (parroquia de la Magdalena) ${ }^{39}$. Por tanto, en la bibliografía general se suele manifestar que Leonardo participó aquí en su etapa de formación ${ }^{40}$, y volvió diez años después como arquitecto consagrado. Sin embargo, con las recientes aportaciones de Higuera Meléndez (2013 y 2014), podemos extraer las siguientes conclusiones. Por su fecha de nacimiento (1654), cuando participó por primera vez en los Venerables (1686-1687) no era tan joven, tenía 32 o 33 años. Por otra parte, en una reciente publicación mía hemos intentado demostrar que, cuando se iniciaron las obras de este hospital en 1676, Leonardo no era un simple aprendiz sino maestro mayor del Hospital de la Caridad (1676-1687) ${ }^{41}$. Con lo cual cambian bastante los esquemas. Por tanto, merece la pena revisar qué es lo que hizo Figueroa en el bienio 1686-1687, ya que no era un modesto albañil sino un acreditado arquitecto, quien en el Hospital de la Caridad había intervenido en las siguientes obras: consolidación de la capilla mayor, con refuerzo exterior de arbotantes; reordenó y reforzó la cripta tras el traslado de los restos mortales de Miguel Mañara; construyó los patios, escalera principal; fachada, que guarda estrecha relación con la de los Venerables; y gran parte de las salas de enfermos.

${ }^{36}$ CRUZ ISIDORO, Fernando: Arquitectura sevillana del siglo XVII..., op. cit., pp.120-121.

${ }^{37}$ Ibidem, pp. 128-129.

${ }^{38}$ FALCÓN, Teodoro: “Algunas puntualizaciones...”, op. cit., pp. 183-193.

39 AGAS, Hospital de los Venerables, leg. 4, lib. 5, p. 4: "En siete días del mes de mayo de mil y seiscientos y noventa y seis, se dio principio a esta obra, para la qual se nombró por Maestro mayor a Leonardo de Figueroa, Maestro Mayor de la obra de San Pablo, al qual se le dieron por aiuda de costa para comprar herramientas doscientos rs. de vn., más de seis rs. de vn. y herramientas que ha de dar para dicha obra".

${ }^{40}$ Se le ha etiquetado como "aprendiz de su compadre Juan Domínguez". CHILLÓN RAPOSO, David: "Nuevas aportaciones...", op. cit., p. 205.

${ }^{41}$ FALCÓN, Teodoro: "Leonardo de Figueroa, maestro mayor del Hospital de la Caridad de Sevilla", Laboratorio de Arte, 29, 2017, pp. 361-393. 
La última nómina en la que figura Juan Domínguez en los Venerables fue en la semana del 25 al 31 de agosto de $1686^{42}$. Debió darse de baja por enfermedad, falleciendo unos años después, el 26 de octubre de 1691. La primera vez que figura Leonardo fue en la semana del 6 al 11 de mayo de 1686. Si comparamos el salario que percibía el maestro Domínguez y Leonardo como oficial, los datos son los siguientes. Domínguez en los seis días laborales percibía 5 reales cada jornada (30 semanales). Sin embargo Leonardo cobraba 10 reales diarios (60 semanales), lo que evidencia que era un arquitecto de prestigio. Entonces Figueroa estuvo al frente de las obras de los Venerables durante poco más de un año, hasta el verano de 1687, cuando se trasladó a Carmona para proyectar y dirigir la construcción de la Casa Rueda. En este corto período de tiempo, intervino en este hospital prácticamente como maestro mayor en funciones. Entonces avanzaron considerablemente las obras de fábrica del hospital y de la iglesia, iniciándose las labores de enlucidos, pinturas murales y decoración, que prosiguieron tras su regreso de Carmona, en 7 de mayo de 1696, en calidad de maestro mayor de esta institución, cuya labor simultaneó con la maestría de las obras del convento de San Pablo (actual parroquia de la Magdalena). Las obras ejecutadas por Leonardo en las dos etapas, las analizaremos globalmente a través de las piezas o espacios más significativos del inmueble, a causa de la breve extensión de este artículo.

\section{LA LABOR DE LEONARDO DE FIGUEROA EN ESTE EDIFICIO}

Se centró principalmente en la construcción de las fachadas y buhardillas (1697-1699); ultimó el patio principal (1696-1699), en el que se realizaron capiteles-ménsula invertidos, tanto en las claves de los arcos de la planta baja, como en los culps de lampe en los que apean los arcos de las galerías. Estos fueron sustituidos en la década de 1930. Figueroa finalizó la escalera principal con la construcción de la bóveda elíptica y su ornamentación, que responde a su estética del barroco polícromo (1686-1697); edificó los cuartos, bajos y altos (1696-1697); construyó íntegramente la fachada de la iglesia, y llevó a cabo la ornamentación interior, en la que destacan los capiteles-ménsulas invertidos de las pilastras y las celosías de las tribunas laterales (1686-1699); construyó la espadaña (1699) y buhardillas que rematan la iglesia, así como la galería del patio ubicado tras la cabecera del templo, que enlazaba el acceso desde la calle Consuelo con los cuartos (Figura 3). La galería se organiza en torno a cinco columnas de piedra blanca traídas de la cantera de Mijas, que labró Silvestre Jordán, a quien se le abonaron 1.300 reales de vellón en 23 de mayo de $1696^{43}$. La portada de la casa del

\footnotetext{
${ }^{42}$ AGAS, Hospital de los Venerables, leg. 4, n 3, Libro de gastos de la obra desde 1684 a 1694.

${ }^{43}$ AGAS, Hospital de los Venerables, leg. 4, n 5, f. 149; y ANGULO ÍÑIGUEZ, Diego: "Casa de Venerables Sacerdotes", op. cit., p. 92.
} 
administrador, que se abre ante un pequeño patio, es obra de Leonardo. Es característica suya la ventana tetralobulada que hay sobre ella. Repite el modelo que este arquitecto empleó en el tambor de la cúpula de la iglesia de San Pablo (La Magdalena) y en su desaparecido claustro (1698-1697). Nos detendremos brevemente en algunas de estas tareas.

\section{EL PATIO PRINCIPAL}

Se hallaba en gran parte acabado cuando en 1696 regresó Leonardo a esta institución como maestro mayor. En 7 de mayo de ese año se pagaron a Melchor Moreno "380 alizares para el patio y ventanas, a siete quartas y media cada una" ${ }^{44}$. Se trata de una partida para el zócalo de azulejos de sus muros y solería de los balcones. El primero y más importante documento gráfico sobre este patio es un lienzo realizado por Lucas Valdés, que se conserva en la actualidad en la galería alta del hospital. Se titula Recibimiento de sacerdotes y peregrinos en el hospital $^{45}$. Se han propuesto varias fechas, pero debemos tener en cuenta que para la realización de las pinturas murales del pórtico de la iglesia se hicieron una serie de pagos por partidas de cal para su mortero base en los años 1698-1699, por lo que este lienzo, que fue un modelo previo, debió realizarse en 1698 cuando el patio estaba completamente terminado. Muestra el frente norte donde se sitúa la iglesia, con la puerta de acceso al templo, sobre la que figura la siguiente inscripción:

\section{DOMVS TVA}

\section{ASILVM MEVM ET REFVGIVM MEVM DOMINE DEVS MEVS}

(Señor Dios mío, tu casa es mi asilo y mi refugio)

Hay otro dato más a tener en cuenta. El patio figura blanqueado, lo que se llevó a cabo en el mismo año de $1698^{46}$. Con relación a los personajes que figuran en la escena se han hecho diversas propuestas, afirmándose que se trata de retratos de Justino de Neve; Fernando Villegas, marqués de Paradas; y los hermanos Colbert ${ }^{47}$. Por nuestra parte desestimamos la presencia de Neve, que había fallecido en 1685. El tener barba y perilla fue común en muchos caballeros de la época. El personaje secular debe ser Pedro Manuel Colón de Carvajal, duque de Veragua y conde de Gelves (1651-1710), patrono de la iglesia. Uno de los clérigos puede ser Luis Corbet, consiliario eclesiástico. El almirante Pedro Colbert

44 AGAS, Hospital de los Venerables, leg. 4, n 5, p. 147. En 7 de abril de 1697 se pagaron 24 reales por "dos sumideros del patio principal de esta obra, y del otro patinillo".

${ }^{45}$ Óleo sobre lienzo, $55 \times 70 \mathrm{~cm}$.

${ }^{46}$ CHILlÓN RAPOSO, David: "Nuevas aportaciones...”, op. cit., p. 225 y nota 128.

${ }^{47}$ AA.VV.: Los Venerables, op. cit., p. 111. 
no figura aquí. Sí se halla en el otro lienzo, La visita a los enfermos en la enfermería baja. Tras él se aprecia un pequeño retablo dedicado a la Virgen. Este recinto se utilizaba entonces para las funciones religiosas, debido a que aún no se había estrenado el templo.

Resulta interesante contrastar el aspecto del patio en el lienzo del Recibimiento, de 1698, con el que tiene en la actualidad. Debemos llamar la atención en él en dos aspectos. Por una parte al comparar los enlucidos. En la actualidad los recercados de los balcones, con sus orejetas, están enlucidos en rojo. En el lienzo de Lucas Valdés se aprecia que estaban en blanco. Además los muros estaban decorados con una hilera vertical de figuras geométricas, a base de cuadrados, rectángulos y óvalos. No figuran en este cuadro zócalos de azulejos. Los que tiene en la actualidad debieron colocarse en 1930 cuando el edificio fue afectado por un incendio parcial. De esta época son las ménsulas que reciben los arcos en los vértices del patio y las que decoran las claves de los arcos de la planta baja. Las que figuran en el cuadro de Lucas Valdés muestran ménsulas invertidas, un modelo que Leonardo empleó en otras construcciones. Su relación por orden cronológico es el siguiente: espadaña del patio del Hospital de la Caridad (1682), capilla mayor de la iglesia de San Vicente (1691-1693), portada del crucero (1691) y cúpula (1696) de la iglesia del convento de San Pablo (parroquia de la Magdalena), patio e interior de la iglesia de los Venerables (1698-1699) y cuerpo de campanas de la torre de la iglesia del Salvador (1718-1719). El modelo lo siguió empleando su hijo Matías en el palacio de San Telmo, bajo las torres del patio principal y en la fachada exterior de la capilla (1730-1734).

\section{ESCALERA PRINCIPAL}

Se trata de una de las piezas más importantes del barroco sevillano. En su primer período (1686-1687), Leonardo construyó la bóveda y se inició su decoración, que continuó a partir de su nueva etapa en 1696. En 23 de abril de 1687 consta que "ajustó el Sr. Administrador la bóveda que se está haciendo y se obligó Leonardo de Figueroa a hacerla por 1.600 rs. de vn. por su trabajo, y costeando el de los oficiales y peones que fueran necesarios" 48 . La escalera es de caja rectangular. Se cubre con bóveda elíptica gallonada, con trompas, decorada con ocho nervios o cintas, de tres segmentos cada una, con yeserías polícromas entre las que figuran con motivos auriculares, inspirados en el tratado de Wendel Dietterlin ${ }^{49}$, más jarrones con flores y cestas de frutos. En la clave ostenta un relieve con el blasón

${ }^{48}$ AGAS, Hospital de los Venerables, leg. 4, no 3 (1684-1694), s. f.

49 FALCÓN, Teodoro: "Influencias de los grabados de Dietterlin en la arquitectura barroca sevillana", Laboratorio de Arte, 21, 2009, pp. 117-134. Esa decoración radial con tres segmentos, se repite en el casquete semiesférico de la iglesia, con pinturas de Valdés Leal. 
de San Pedro, uno de los titulares del templo, con la mitra y las llaves. En la base de la bóveda figuran cabezas de querubines y ocho ángeles niños a modo de atlantes, motivo que se repetirá en la fachada de la iglesia a calle Jamerdana. Toda esta decoración escultórica debió correr a cargo del maestro escultor del hospital, Juan de Oviedo ${ }^{50}$. Cuando Figueroa regresó a esta institución en mayo de 1696, en calidad de maestro mayor, prosiguió las tareas complementarias de esta escalera que culminaron al año siguiente. Entre ellas destacaremos la realización de la balaustrada de hierro. La balaustrada, que se halla en el segundo tramo, tras el descansillo, fue ejecutada por el maestro herrero Pedro Muñoz. En 16 de marzo de 1697 se pagó a Juan López 100 maravedíes "por la bola (dorada) que está en la escalera" ${ }^{1}$. Se encuentra sobre el pilar de hierro en el inicio de la balaustrada. En 1696 se hizo una ventana ovalada en la escalera, decorada con una vidriera ${ }^{52}$. En su lugar hay hoy, hacia el interior de la escalera, una ventana rectangular con rejas, que recibe luces de los balcones de la galería alta.

\section{LA IGLESIA}

Se halla ubicada en la crujía norte. Es de una nave, de planta rectangular, con testero plano y nártex a los pies, modelo tomado de fray Lorenzo (Laurencio) de San Nicolás, de su tratado Arte y uso de la Architectura ${ }^{53}$. El cuerpo de la iglesia es de cuatro tramos, siendo el mayor el del antepresbiterio, de planta cuadrada, cubierto con una bóveda semiesférica sin tambor. Los demás tramos se cubren con bóvedas de cañón con lunetos y arcos fajones. La nota barroca no la pone la arquitectura, sino su decoración, a base de retablos, celosías de las tribunas, púlpito, pinturas murales y de bóvedas, así como la decoración exterior de la fachada de los pies. Durante la primera etapa de Leonardo (1686-1687) este arquitecto percibió unos pagos por enlucir la capilla mayor ${ }^{54}$ y se pusieron andamios

${ }^{50}$ Este artista no debe confundirse con su homónimo Juan de Oviedo y de la Bandera (1565-1625), arquitecto, escultor e ingeniero militar.

${ }^{51}$ AGAS, Hospital de los Venerables, Libro de la obra que por quenta del Ilmo. Sr. D. Jaime Palafox y Cardona, arzobispo de Sevilla se está haciendo en esta casa de Sres. Venerables Sacerdotes en dicha ciudad, p. 153v.

52 Ibidem, 24-11-1696, p. 153: "Pagué más al maestro herrero por 54 libras de hierro para la vidriera de la escalera...". "En 29 de dicho [noviembre] se pagó por el porte de la vidriera de la escalera y del óvalo de alambre que está por la parte de afuera, 1 rs. y 2 mrs.”. "En 8 de diciembre pagué por la vidriera que está en el óvalo de la escalera 228 rs. de vn. en los quales entra el óvalo de alambre de dicha vidriera".

${ }_{53} 1^{\text {a }}$ parte: Madrid, 1639. $2^{\mathrm{a}}$ parte: Madrid, 1665.

${ }^{54}$ AGAS, Hospital de los Venerables, leg. 4, no 3. Libro de gastos de la obra (16841694), s. f. "Esta semana [25 a 31 de agosto de 1686] se acabó la obra de la casa y sacristía por ahora y se prosiguió el enlucir de blanco la iglesia, la cual se ajustó con Leonardo en ochocientos reales, porque igualase la capilla mayor con la de la iglesia". "Prosiguió 
para que Valdés Leal realizara sus pinturas ${ }^{55}$. Además se hicieron las gradas de acceso al presbiterio por los maestros canteros Francisco Jordán y Francisco Gómez Septier ${ }^{56}$ y se mudaron las tribunas. A ellas se alude por primera vez en 1675 en la escritura de donación del solar por parte del duque de Veragua, mediante la cual Colón de Portugal exigía, entre otras condiciones, disponer de una tribuna que comunicara a través de un pasillo con sus casas principales ${ }^{57}$. Creemos que debía estar en el lado de la epístola, ya que esas casas tendrían que estar en la calle Consuelo.

La documentación alude al inicio de la construcción de las tribunas en 1686. Consta que, en 22 de septiembre, "a tres maestros de albañilería que se juntaron para la disposición de la tribuna y se les dio 6 pesos" 58 , y, meses después, "prosiguió Leonardo en las obras de la iglesia para enmendar las tribunas desde el día 11 de marzo de 87". Cuando en verano de ese año el arquitecto se estableció en Carmona, prosiguió la dirección de las obras José Tirado. Las celosías de las tribunas se ejecutaron en 1686 por el maestro de carpintería Juan de Oviedo. La del lado de la epístola se hizo sobre el retablo de la Inmaculada Concepción (Asunción) que hizo Murillo (la Inmaculada del mariscal Soult). Hace años documenté que la Hermandad de los Venerables la adquirió en 1686 de la testamentaría de Justino de Neve, por acuerdo capitular de 22 de septiembre de ese año, por lo que coincide la realización del retablo y tribuna con ese hecho ${ }^{59}$. Las celosías se decoran a base de motivos vegetales y de los blasones alusivos a San Pedro y San

Leonardo a enlucir el presbiterio a jornal desde el 24 de septiembre de 86 ". 30 de octubre: "A Leonardo por haber acabado el presbiterio, de ayuda de costa, 50 rs.".

55 Ibidem. En 15 de enero de 1686 consta que "prosiguió Valdés con la pintura y se pusieron diferentes andamios en que se ocupó 8 peonadas, a 3 reales y medio". "Más 500 rs. que en 24 de enero de 1688 se pagaron a Juan de Valdés de último resto de lo que importó la pintura de la capilla mayor".

${ }^{56}$ Ibid., leg. 4, nº 3 (1684-1694), s. f. "Ajustáronse las gradas del presbiterio de la iglesia con Francisco Jordán y Francisco Gómez, maestros de cantería en precio de 90 rs. de vn. La vara y media, se dio a cuenta 500 rs. de que dieron recibo".

${ }^{57}$ QUILES, Fernando: Teatro de la Gloria, op. cit., pp., 384-385. "Y se le darán a Su $\mathrm{Ex}^{\mathrm{a}}$ dos tribunas, una alta y otra baja, con tal calidad de que en caso que se dé dicha tribuna baja no ha de tener puerta que salga a la iglesia, sino reja cerrada, y asimismo con declaración que mediante que de muchos años a esta parte los Exmos. Señores de Veragua, condes de Gelves, no han estilado vivir y habitar dichas sus casas principales a que han de corresponder dichas tribunas y la suelen vivir diferentes personas y no parece justo que el uso de ellas sea común, sino solamente reservado a la grandeza de $\mathrm{Su} \mathrm{Exc}^{\mathrm{a}}[\ldots]$ ".

${ }_{58}$ AGAS, Hospital de los Venerables, leg. 4, $\mathrm{n}^{\circ} 3$.

${ }^{59}$ FALCÓN, Teodoro: “Algunas puntualizaciones...”, op. cit. pp. 187-188. La realización del cuadro de Murillo se fecha ahora entre 1660-1665. Véase AA.VV.: Murillo y Justino de Neve, op. cit., pp. 114-115. 
Fernando. Fueron doradas en $1698^{60}$. La otra tribuna se sitúa sobre el retablo de Cristo crucificado, en el lado del evangelio.

A su regreso, a partir de mayo de 1696, en calidad de maestro mayor de este hospital, la participación de Figueroa en la iglesia, hasta su estreno tres años después, la sintetizaremos en virtud de los límites de ese artículo. Entre la decoración arquitectónica hay que destacar las ménsulas invertidas que hacen función de capiteles en las pilastras de los muros laterales (Figura 4). Debemos destacar las portadas laterales del presbiterio, adinteladas y flanqueadas por pilastras, con ménsulas invertidas haciendo función de capiteles, de las que penden un modelo de pinjantes con gotas, semejantes a las que hay en los cimacios de las columnas del pórtico de la iglesia. Rematan en un frontón roto y enroscado, sobre los que se elevan sendas hornacinas de perfil trilobulado, que albergan riquísimos relicarios - de Santa Hantosa y de Santa Victoria-. La espadaña se eleva sobre el teórico crucero, muro de la epístola, a eje de él. Queda un tanto empequeñecida por el volumen de la cubierta a cuatro aguas del teórico crucero (Figura 5). Es de fábrica de ladrillo. Consta de dos vanos con arcos semicirculares para albergar sendos campanarios. Se remata en un frontón de triple inflexión, sin duda inspirado en los que diseñó Hernán Ruiz II en el cuerpo de campanas de la Giralda. El campanario no es visible desde el exterior. Su mejor perspectiva se aprecia desde el mirador existente sobre la actual sala de lectura, en el ángulo suroeste de la segunda planta. En enero de 1698 aún no estaba construido. En cabildo de 11 de enero de ese año consta el estado en que se hallaba el edificio: "Acabada la iglesia nueva y perfeccionado el cielo de ella y hechos los altares y puestas las gradas de ellas, aunque todavía no hay hecho campanario, ni retablo [mayor], ni medios para hacerlos, ni esperanza próxima" ${ }^{61}$. La espadaña se edificó un año después bajo la dirección de Leonardo de Figueroa. Constan diversos pagos realizados al maestro carpintero Francisco Díaz de Angelina, al herrero Pedro de Carmona por los remates "de la torre", y al pintor Juan Neira por enlucirla de cal y almagra, así como pintar en ella los blasones de San Pedro y San Fernando ${ }^{62}$.

${ }^{60}$ ANGUlO ÍÑIGUEZ, Diego: "Casa de Venerables Sacerdotes", op. cit., p. 88. Cita pagos a Francisco de Angelina (Díaz de Angelina) por hacer los andamios. CHILLÓN RAPOSO, David: "Nuevas aportaciones...", op. cit., p. 222.

${ }^{61}$ AGAS, Hospital de los Venerables, leg. 1, n 7, Libro de Acuerdos de esta Casa desde el año de 1698 hasta el de 1770, f. 20v.

${ }^{62}$ Ibidem, leg. 4, lib. $4^{\mathrm{a}}$, Sumario de gastos. Cuenta de la obra de la iglesia, torre y cajonería de la sacristía y altar de Santa Teresa (1694-1699), ff. 53 y 54. En 1921 se repararon la espadaña y las cubiertas del teórico crucero bajo la dirección desinteresada del arquitecto Juan Talavera Heredia. AA.VV.: Los Venerables, op. cit., p. 31. 
Con relación a la fachada principal del templo, con su pórtico y nártex hubo una gran actividad entre 1691-169963. La fachada se organiza en tres alturas. La planta baja consta de un triple pórtico de arcos semicirculares, sobre columnas pareadas de mármol blanco (Figura 6). Sus rejas se colocaron en 1698, siendo realizadas por Pedro Muñoz, maestro herrero que realizó también las rejas de los cuartos y balcones ${ }^{64}$. El segundo cuerpo se asemeja a un retablo barroco (Figura 7). El vano central muestra una hornacina, con remate de venera, que alberga la imagen de San Fernando. Sobre ella hay la talla de un ángel niño, semejante a los que decoran la bóveda de la escalera principal. Rivas Carmona (1994) ya advirtió el paralelismo de los soportes retallados con los retablos de Bernardo Simón de Pineda. Por nuestra parte habíamos indicado que parte del rico repertorio ornamental, a base de figuran fantásticas y determinados soportes, están extraídos del tratado de Wendel Dieterlin ${ }^{65}$. Respecto a los frescos pintados en los muros laterales del nártex, ahora apenas visibles, ya hemos manifestado que representaban los temas que figuran en los lienzos preparatorios de Lucas Valdés (1698), alusivos, el de la izquierda, a La llegada al hospital de sacerdotes y, el de la derecha, a la Visita del almirante Colbert a los enfermos acogidos ${ }^{66}$.

Fecha de recepción: 3 de octubre de 2010

Fecha de aceptación: 30 de enero de 2018

${ }^{63}$ AGAS, Hospital de los Venerables, lib. 3, Gastos de la obra (1684-94): "Más se ha gastado hasta fin de junio de 91 en la obra del pórtico en cal, ladrillo y más setecientos y noventa y dos reales".

${ }^{64}$ Ibidem, lib. 4, Sumario de gastos. Cuenta de la obra de la iglesia, torre..., f. 23.

${ }^{65}$ RIVAS CARMONA, Jesús: Leonardo de Figueroa: una nueva visión de un viejo maestro. Sevilla, 1994, pp. 58-59; FALCÓN, Teodoro: "Influencia de los grabados de Dietterlin...", op. cit., pp. 121-122; y MORALES MARTÍNEZ, Alfredo J.: "Leonardo de Figueroa y el barroco policromo de Sevilla", en Figuras e imágenes del barroco. Estudios sobre el Barroco español y sobre la obra de Alonso Cano. Madrid, 1999, pp. 193-209.

${ }^{66}$ Constan varios pagos por el mortero de cal que hay bajo ellas. En 29 de mayo de 1698 se libraron 37 reales y medio "por cahiz y medio de cal que ha enviado [el maestro calero] para la pintura que se ha de hacer al fresco en el pórtico" y en 13 de marzo de 1699 está fechada esta minuta: "pagué por una carga de cal que se trajo para el pórtico, seis reales de vellón”. ANGULO ÍÑIGUEZ, Diego: "Casa de Venerables Sacerdotes”, op. cit., doc. 5 , p. 90 . 


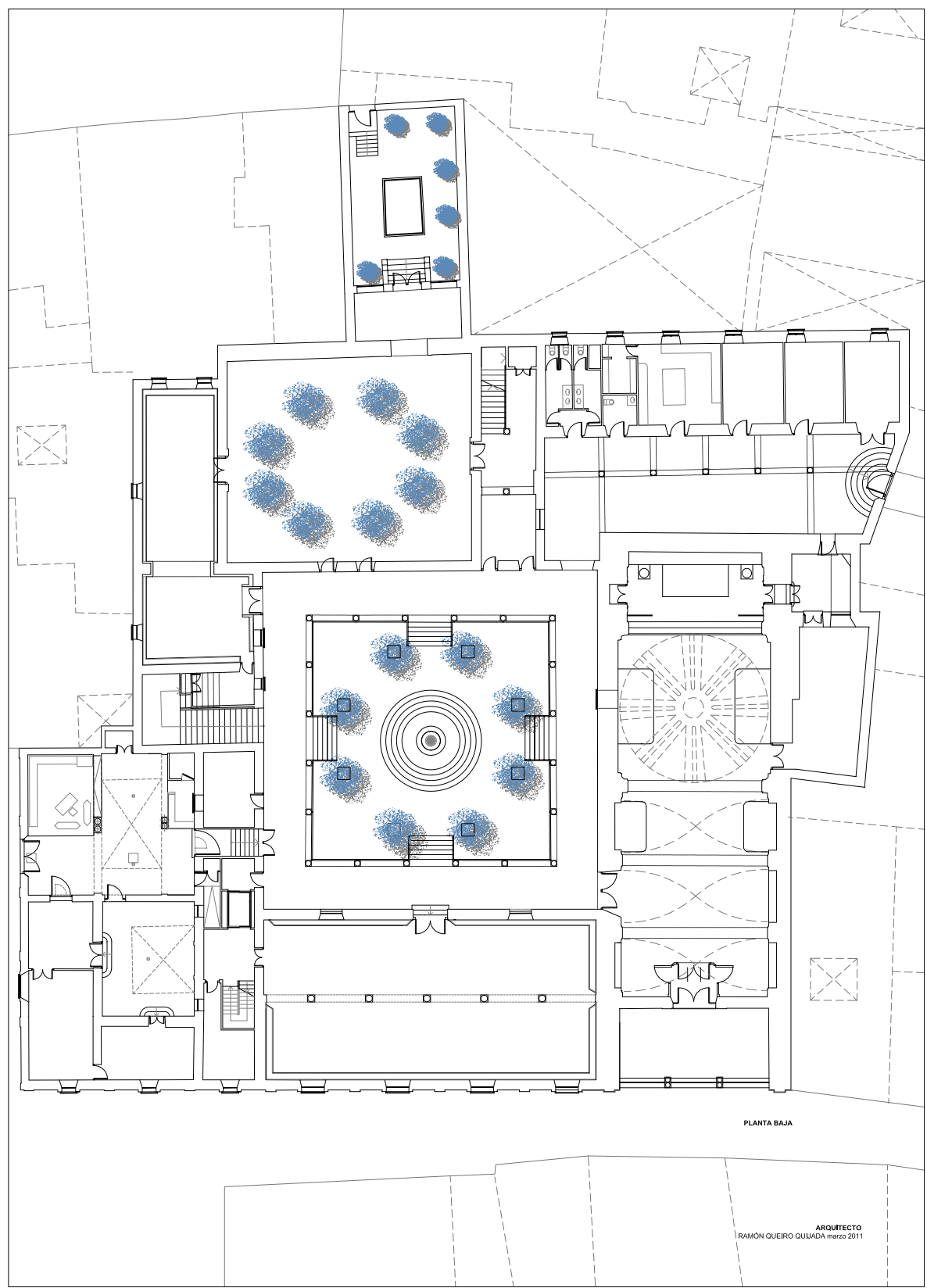

Figura 1. Planta baja. Plano: Ramón Queiro Quijada. 


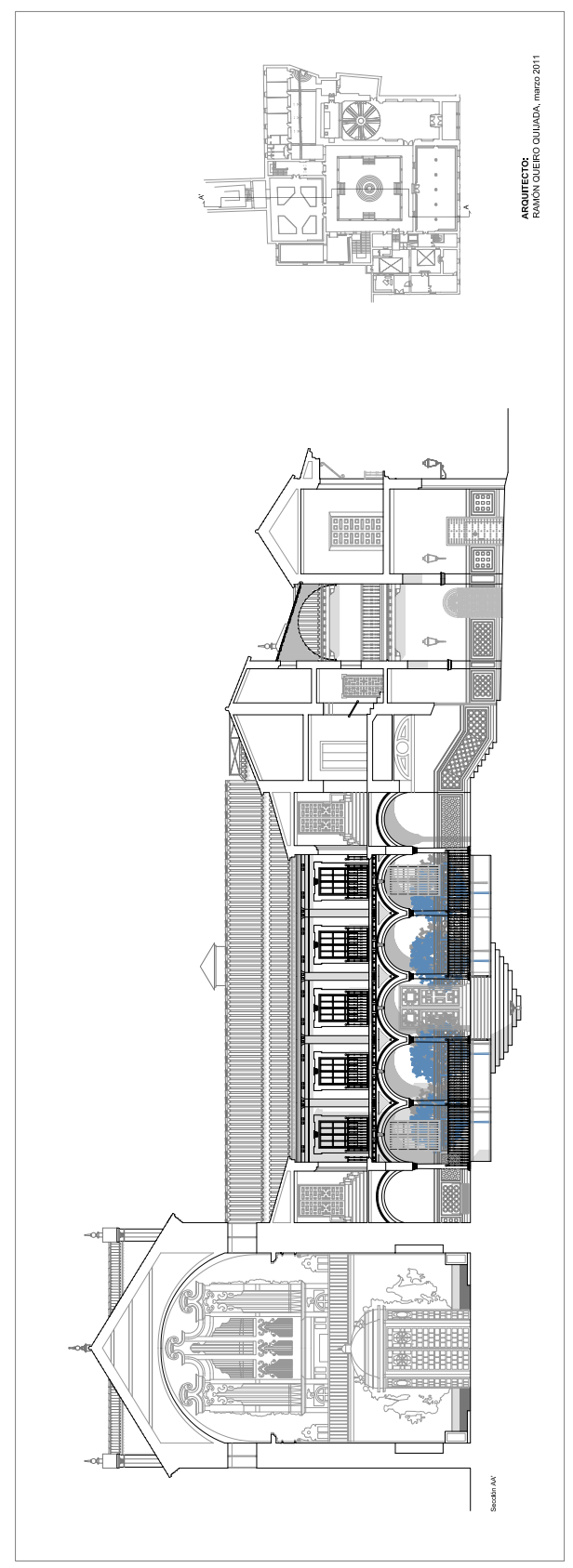

Figura 2. Sección longitudinal.

Plano: Ramón Queiro Quijada.

LABORATORIO DE ARTE 30 (2018), pp. 143-166, ISSN 1130-5762

e-ISSN 2253-8305 - DOI http://dx.doi.org/10.12795/LA.2018.i30.08 


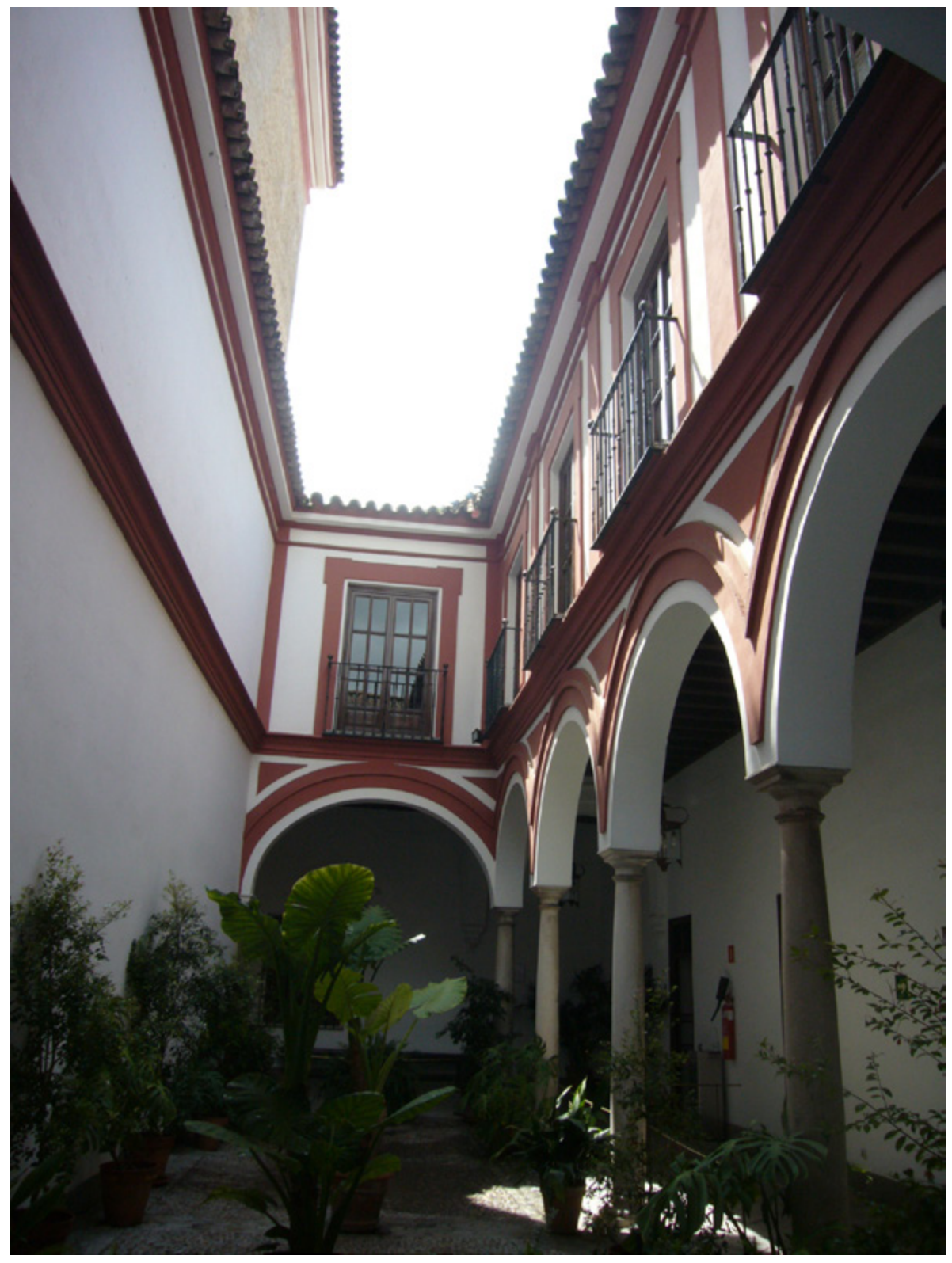

Figura 3. Patio y galería existente tras la cabecera de la iglesia. Foto: Teodoro Falcón Márquez. 


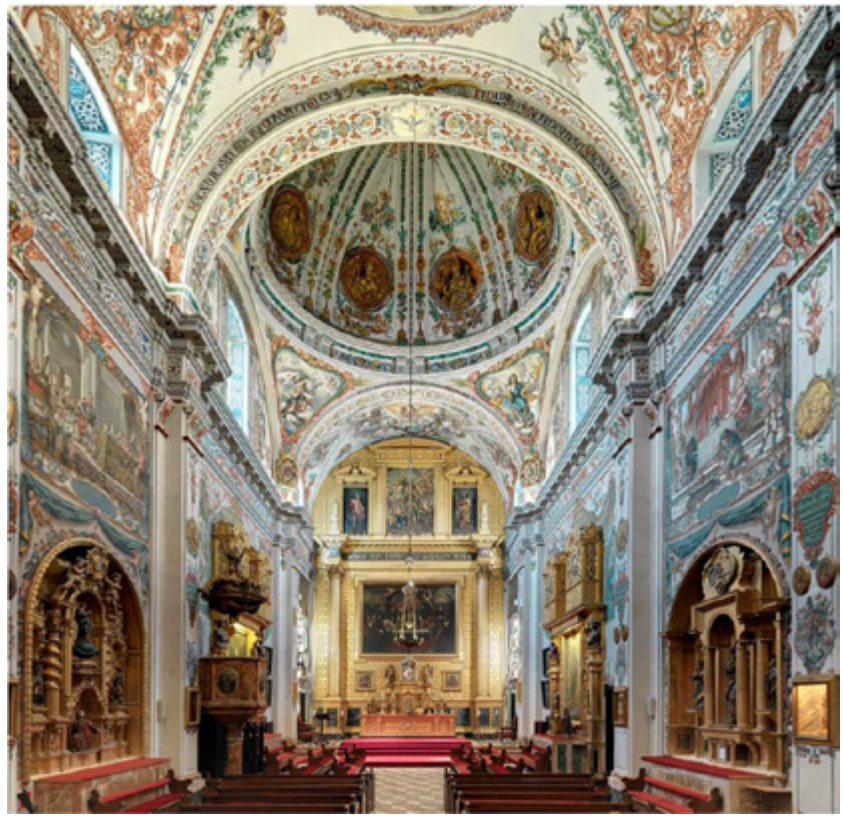

Figura 4. Interior de la iglesia. Foto: Teodoro Falcón Márquez.

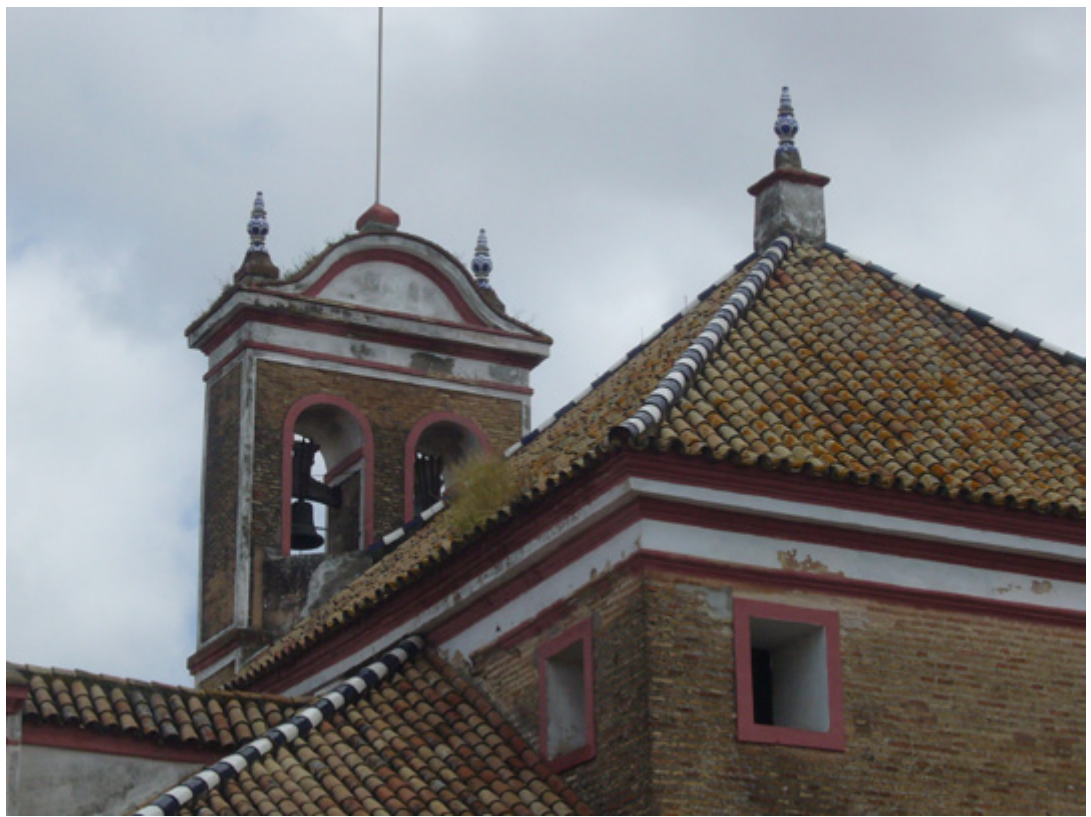

Figura 5. Espadaña y cubierta del teórico crucero. Foto: Teodoro Falcón Márquez.

LABORATORIO DE ARTE 30 (2018), pp. 143-166, ISSN 1130-5762 e-ISSN 2253-8305 - DOI http://dx.doi.org/10.12795/LA.2018.i30.08 


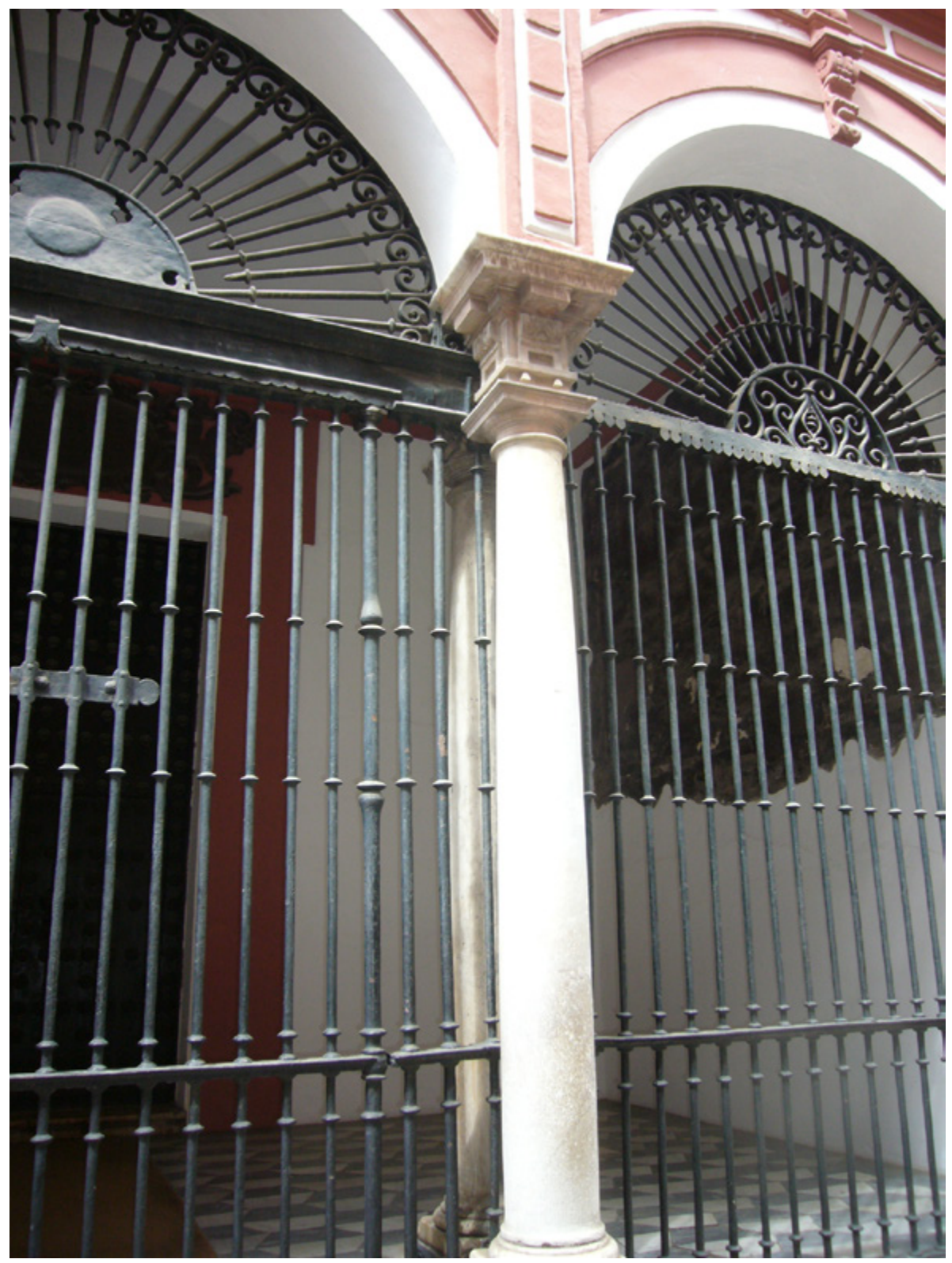

Figura 6. Vestíbulo de la iglesia. Foto: Teodoro Falcón Márquez. 


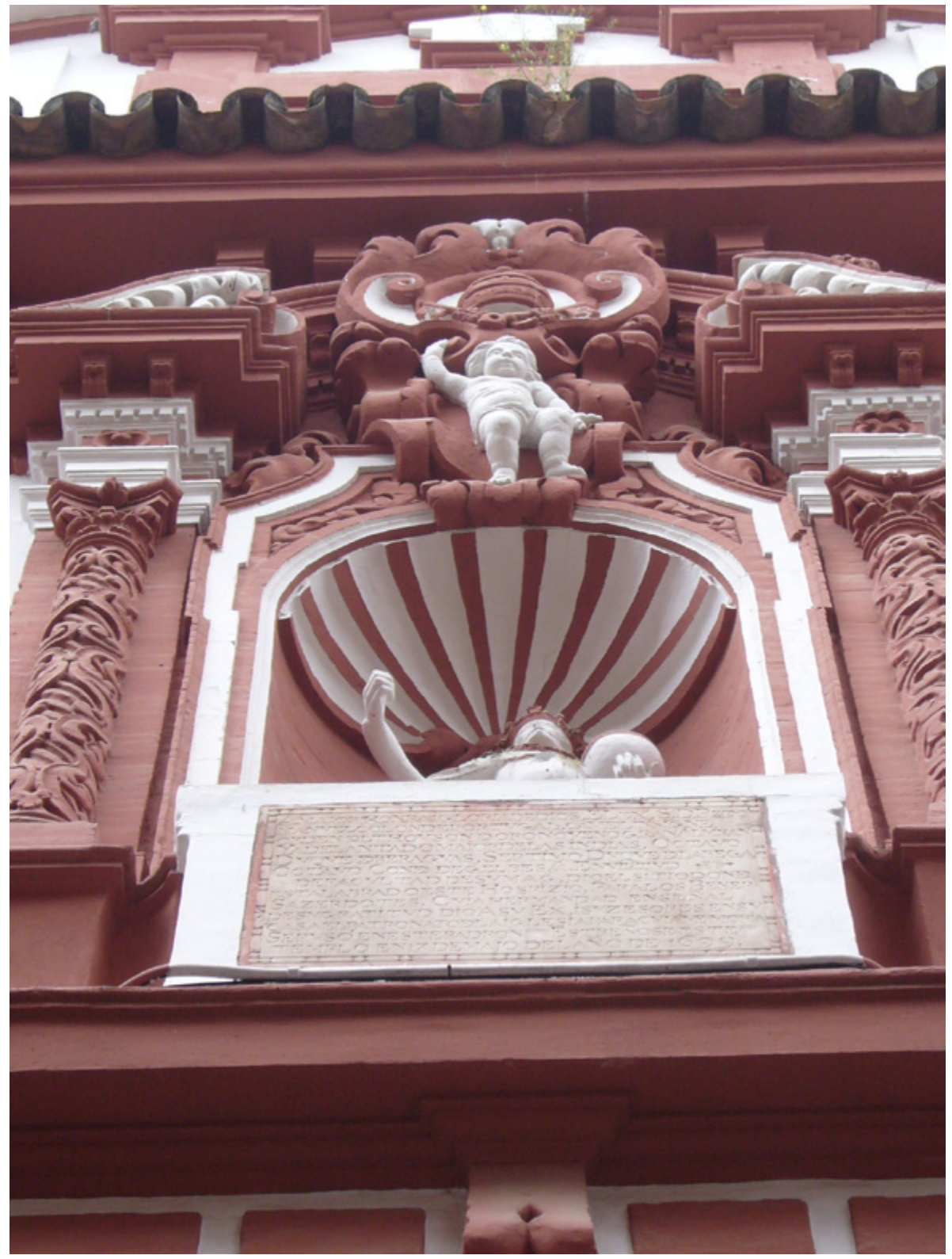

Figura 7. Segundo cuerpo de la fachada. Foto: Teodoro Falcón Márquez. 